\title{
The differential effects of syntactical pairings on cued recall and recognition*
}

\author{
ANDREW MANFRED OLSON \\ Brooklyn College of the City University of New York, Brooklyn, New York 11210
}

\begin{abstract}
Tulving and Thompson's (1973) procedure was used to test for both cued recall and recognition of the same set of target words. Analyses indicated that performance on the former was superior. However, if the kind of "syntactical" pairing (noun-adjective, verb-noun or noun-noun) was examined, the effect was restricted only to the noun-adjective pairs. These results suggest a limitation in the generality of Tulving and Thompson's (1973) encoding specificity hypothesis and raise the possibility that their results were artifactual.
\end{abstract}

Tulving and Thompson (1973) demonstrated that when Ss were induced to encode words in the "context" of another word and then were tested both with a cued recall task and a recognition task, they were able to recall more words than they could recognize. This was so even though the target word (to-be-remembered word) was a weak associate of the cuing word-1\% using the Bilodeau and Howell (1965) and Riegel (1965) free association norms. In this respect, their procedures extended the research investigating the conditions that lead to higher recall than recognition (Bahrick \& Bahrick, 1964; Lachman \& Field, 1965; Lachman, Laughery, \& Field, 1966; and Tulving, 1968).

Tulving and Thompson (1973) argue that what is stored about a word on a list is information about the specific encoding of that word in the task context. The stored information may or may not include the target word's relationship with some other word (or words). If so, then the associated word may be an effective retrievel cue; if not, then it cannot give access to the stored word.

The present experiment was prompted by an examination of Tulving and Thompson's (1973) results and preliminary pilot work which replicated their basic results. In both sets of data, it was observed that the word pairs could be classified as noun-adjective (NA), verb-noun (VN), and noun-noun (NN), and that the difference in recall and recognition may have been related to the noun-adjective pairs. The present study further investigates this finding.

\section{METHOD}

\section{Subjects}

The $\$$ s were 16 male and female Brooklyn College students, members of introductory psychology classes, who volunteered to participate.

\footnotetext{
Materials

Three lists of 21 word pairs each were used, selected from

*Special thanks to Solomon Weinstock for his comments on the manuscript and to Charles DeVito on the analysis of the data. Sponsored by Ralph R. Miller, who takes full editorial responsibility for its contents.
}

Tulving and Thompson's (1973) list. The first member of each pair (lowercase) was the cue word; the second member (uppercase) was the target word. All target words were low-frequency associates to its weak cue (Bilodeau \& Howell, 1965; Riegel, 1965; Palermo \& Jenkins, 1964). For the critical third list, the 21 pairs were divided into three groups: 7 noun-adjective pairs (stomach-LARGE, train-BLACK, stem-SHORT, butter-SMOOTH, glass-HARD, cave-WET, and ground-COLD); 7 verb-noun pairs (glue-CHAIR, grasp-BABY, whistle-BALL, roll-RUG, think-STUPID, exist-BEING, and beat-PAIN); and 7 noun-noun pairs (lady-QUEEN, art-GIRL, mountain-TREE, plant-BUG, spider-BIRD, fruit-FLOWER, and cloth-SHEEP).

Also used was a listing of four words generated as free associates, in a previous task by other Ss, to a high-frequency associate to each of the target words on the third list. Included in the four words was the target word.

\section{Procedure}

Each S was presented three successive lists. The purpose of the first two lists was to establish the "encoding context" for the target words. The target words, each paired with its cue word, were presented visually via a Kodak Carousel $800 \mathrm{H}$ programmable projector, one at a time in random order, at a 5 -sec rate. Immediately after presentation (for Lists 1 and 2), the Ss were given the input cue words in a random order and instructed to write down the target words.

The critical third list was presented in the same way as the first two. After presentation, however, the Ss were asked to perform a recognition task, where they were to examine the free associates, generated by others, to strong associates to the target words, and write down those words they recognized as the target words. Immediately after this was done, Ss were given the 21 input cues for the third list and asked to recall as many words as they could. Three minutes were allowed for cued recall of target words for all lists.

\section{RESULTS AND DISCUSSION}

Table 1 shows the mean number of target words

Table 1

Mean Number of Target Words Recalled and Recognized as a Function of Type of Syntactical Pairing

\begin{tabular}{ccccccc}
\hline & \multicolumn{3}{c}{ Recall } & & \multicolumn{4}{c}{ Recognition } \\
\cline { 6 - 7 } NA & VN & NN & & NA & VN & NN \\
\hline 4.74 & 4.25 & 4.69 & & 3.25 & 3.81 & 4.63 \\
\hline
\end{tabular}


recalled and recognized as a function of type of syntactical pairing.

A two-factor repeated measures analysis of variance was done and indicated that the effect of test procedure (recall vs recognition) was significant, $\mathrm{F}(1,15)=5.393$, $\mathrm{p}<.05$. While there was no significant effect of pairings (NA, VN, and NN), there was a significant interaction of these two variables, $\mathrm{F}(2,30)=6.275, \mathrm{p}<.05$.

Because of the significant interaction observed, correlated $t$ tests were done comparing performance for each of the types of pairings under the two test procedures. This analysis indicated that performance differed only for the NA pairings, $\mathrm{t}(15)=3.87, \mathrm{p}<.05$.

The present study strongly suggests that the Tulving and Thompson (1973) results were due to differences in recall and recognition only on the noun-adjective pairings. The current findings lead, minimally, to the questioning of the generality of the notion of encoding specificity. They suggest, at worst, that the earlier findings were artifactual.

\section{REFERENCES}

Bahrick, H. P., \& Bahrick, P. O. A re-examination of the interrelations among measures of retention. Quarterly Journal of Experim ental Psychology, 1964, 16, 318-324. Bilodeau, E. A., \& Howell, D. C. Free association norms.
(Catalog No. D210.2:F87) Washington, D.C: U.S. Government Printing Office, 1965.

Lachman, R., \& Field, W. H. Recognition and recall of verbal material as a function of degree of training. Psychonomic Science, 1965, 2, 225-226.

Lachman, R., Laughery, K. R., \& Field, W. H. Recognition and recall of high frequency words following serial learning. Psychonomic Science, 1966, 4, 225-226.

Palermo, D. S., \& Jenkins, J. J. Word association norms. Minneapolis: Unniversity of Minnesota Press, 1964.

Riegel, K. F. Free associative responses to the 200 stimuli of the Micihgan restricted associative norms. USPHS Technical Report No. 8, Grant MH 07619, University of Michigan, 1965.

Tulving, E. When is recall higher than recognition? Psychonomic Science, $1968,10,53-54$.

Tulving, E., \& Thompson, D. M. Encoding specificity and retrieval processes in episodic memory. Psychological Review, $1973,80,358-372$.

(Received for publication December 31, 1973.) 